\title{
Digital Colonialism on Digital Natives: A WhatsApp Usage Perspective
}

\author{
Ruth Karachi Benson Oji \& Emmanuel Ezimako Nzeaka \\ http://dx.doi./org/10.4314/ujah.v21i1.2
}

\begin{abstract}
In the new media debate, digital colonialism has become a topic of serious contention. This work looks into the allegation that the internet is exploitative of digital natives' daily routine and regulates their lives. This study explores this argument in relation to the degree of consciousness of digital natives to seek out their perception of politics of Western domination in the WhatsApp usage. Therefore, the primary purpose of this paper is to find out whether digital slavery is real. Centre Periphery theory and Electronic Colonisation theory form the theoretical background of the study, which utilised questionnaires to determine areas of controversy. Using survey, we found that digital natives do not count the use of the WhatsApp as an element of colonialism. Consequently, $53.26 \%$ of the natives do not consider themselves enslaved to WhatsApp usage and thus its colonial powers; however, $28.26 \%$ view themselves as willing slaves consequent on the benefits from using the App, while an $18.48 \%$ are unsure of their position. Based on the results, it is argued that the concept of digital slavery in terms of absolute dependence on WhatsApp does not quite appeal to digital natives, except that the amount of time they spend on it could make them enslaved, whether or not they agree. To be surer of the level of influence of internet based apps on digital natives, it is recommended that further studies be conducted that will investigate the amount of time they spend on other apps, using a wider sample population.
\end{abstract}


Keywords: Digital Colonialism, Digital Natives, WhatsApp Usage, Western Domination, Electronic Colonisation

\section{Introduction}

"Data is [sic] not the new oil. It is the new land that is being rapidly colonised by corporations with the means to exploit this new resource"' (Smith, 2016 p.1). Colonialism, as conceptualised, has migrated from acquiring physical space to acquiring the human mind through the media. It has become a kind of psychological imprisonment through repetitive mass media and meddlesome digital manipulative messages that are channeled towards the entrapment of the eyeballs, ears, soul, attitude and disposition of the public. It does not require any coercive physical action or the conquering of any territory by the army of fortune claiming to be on a civilising mission but works its way through subtle persuasive packaging to enslave large audiences and nations.

The internet's extraordinary nature is coupled with that of the imperialist period. In the past, colonial land ownership was a matter of capital accrual, but now stakeholders are digital topographers, generating cybernetic space to discover new commercial territories. They are creating new territory and workforce through technological firms, a variety of digital colonial hierarchy. Jandrić and Kuzmanić (2015) corroborate this statement by insisting that the ancient standard of producing the savage is a purely moving course: instead of making the savage from individuals found in the new terrains, digital colonialism has moulded the savage from persons who are left behind in the old milieu. This digital psychological empire uses the means of hegemonic language (in this case English) projected by the dominant media to acquire and enslave people all over the world (Omoera, 2010). The digital colonialism is championed by the Global North, as it was in the colonial era, through behemoth media multinationals like Google, Facebook, WhatsApp, Twitter and a host 
of others. They have corralled the Global South with a plethora of media products that are very difficult to resist or ignore, due to a lack of capacity to wedge this influence, so the Global South consumes whatever that is produced by the West. This is the thrust of the new digital colonialism. The way this happens and the impact on individuals is the principal concern of this paper because there is a tacit link between colonial legacies connected with western industrial development, market consumerist tradition and digital imperialism as they possess the same pattern of consumer universal culture (Iqani, 2017). Ali (2017) in the same vein observes that "the invocation of colonialism in informative discourses include explicit recognition within the discipline of 'postcolonial computing' of a 'colonial impulse' within ubicomp, analogically formulated with reference to $18-19^{\text {th }}$ century British colonialism'” (p.3).

Digital colonialism includes not only the ability of the media to regulate the activities of individuals but also of institutions and even nations through the internet, technology and the mass collection of data to predict, influence and disrupt behaviours (Mills et al, 2016; Torbel, 2019). This means that social networking sites also have in possession our daily comportment that would enable them to manipulate our lives and that of nations. For instance, Cambridge Analytica, a network company working with Facebook has been able to disrupt the political life of countries like Kenya, Nigeria, Bolivia, Latvia, and probably the United States, by influencing the outcomes and mining of the data of opposition politicians (Blumenthal, 2018; Solon, 2017). These western media conglomerates have taken the advantage of the digital vacuum to invest heavily on the internet and artificial intelligence to regulate all aspects of our life, thereby challenging individuality and threatening the security of nations (Eijaz \& Ahmad, 2011). They have gone beyond national boundaries and cultures to mine data which they use for the control of individuals and for profit. In accordance with this position, Jin (2015) points out 
that "platform owners who are mega media and technology giants have developed their strategies to appropriate user activities in order to transform users' daily performances in monetary revenue resources" (p.185). Anderson cited in Smith (2016) also gives an insight into the gain they have made by mining the data:

We need to look no further than Microsoft's USD 26 billion acquisition of LinkedIn or Facebook acquisition of WhatsApp for USD 19 billion and Instagram for a mere USD 1 billion and AT\&T's USD 14.2 billion valuation of the value of its data assets as stated in annual reports. When you investigate the values involved in data assets, the figures are staggering. It would be fair to say that most people have no idea how much their data is truly worth. (p.2)

Thus, these global brands would "colonise weak local practices and at worse erase and at best, appropriate and profit from them" (Iqani, 2016). For example, about $90 \%$ of the internet and media consumables in Nigeria are imported from the West. The IT companies are mainly engaged in maintenance and add-on on finished products. Some are not aware that this vacuum has created a "digital productivity gap" that is exploited by the conglomerates because they are in perpetual control of search algorithms, thereby monitoring and determining digital platforms and universal culture.

This control of the media and digital space by the Global North has led to the psychological imprisonment of the digital natives in the Global South who have albeit unwittingly migrated into the digital colonialism with relish. Today, a generation of young people born into the internet era is immersed in the digital world. Researchers believe that their brains are wired differently by internet technology because of early involvement with technology (Lin, 2008; Herther, 2009; Crist, 2017). In consonance with this observation, Dingli \& Saychell (2015) see them as individuals bound by technology from their birth. Being bound means that they are in 
certainty exposed from birth to technology. These natives are influenced heavily by internet conglomerates and prefer receiving information and processing it at the speed of light as they adhere to multitasking and active learning (Prensky, 2001). They are born into the colonial culture of Apple, Facebook, WhatsApp, Uber, Taxify, Twitter and a host of other pervasive Apps perpetrated by the conglomerates of the Global North that have infiltrated their lives to the point of omniscience that they have adopted it as part of their culture (Patson, 2014).

Based on the aforesaid, this paper looks at how digital natives conceptualise digital colonialism. Do they see it as a reality or a fallacy? Have they willingly accepted to be addicted to the internet conglomerates because of the perceived benefits? Particularly, to help people relate to the current criticism, this paper investigates the level of digital colonialism among digital natives in a Nigerian tertiary institution through the media messaging application - WhatsApp (assumed to be the most popular App among the youth in Nigeria) (Cchub, 2014; Muyiwa 2015; Smith, 2017; Similarweb, 2018).

There is need for the conceptualisation of the following terms to aid our understanding of the issues discussed in this paper:

\section{Digital Slavery}

Slavery has been since the existence of homo sapiens. It is a condition in servitude in which a human being, after purchase, is subjected to the whims and caprices of another person. They are perpetually attached to the purchaser who is at will to use them as he/she deems fit. As Ogunsola (2005) points out, "Another characteristic of slavery is the fact that the slave was deprived of personal liberty and the right to move about geographically as he/she desired". The main thrust here is that a slave is eternally attached to the master who has bought him or her. At this juncture, one may wonder how this is related to the notion of digital slavery. The old slavery involved geographical 
conquest and then subjugation by a stronger party, while digital slavery is about the conquest of the territory of cognition and the mind by devices developed by the conglomerates as we know them: Facebook, Google, Twitter, WhatsApp, Netflix, Uber, and a host other internet Apps. According to Rogerson (2018), just like in the physical slavery, new groups of people arrive and settle permanently while retaining commitment with the homeland. The virtual world is undergoing colonialism. The conglomerates show a permanent identity and are sustaining permanent manifestations. Their modus operandi remain aligned to the organisation and the location they come from (The United States and Europe - the Global North). The present aboriginal virtual inhabitants are forced to align to the dictates of the colonisers and they stand the danger of being forced to conform to the dictates of slavery and servitude of the settlers, being pressurised into conforming to the norms of the new virtual settlers.

Therefore, digital slavery from our conception is that sense of physical and emotional attachment to technology, in this case internet applications, to the extent that it regulates one's life. This may originate from an overt connection to internet devices to the extent that there is a dependency syndrome, that an individual feels distraught without it. It is a constant desire to be online to the stratum. Digital slaves are not able to master the technological world effectively; instead, they are enslaved by it (Moody, 2014; Illing, 2018). Anderson (2010) captures this situation graphically:

You wake up and check your email on your bedside iPad that's one app. During breakfast, you browse Facebook, Twitter, and The New York Times - three more apps. On the way to the office, you listen to a podcast on your smartphone - another app. At work, you have Skype and IM conversations. More apps. At the end of the day, you come home, make dinner while listening to Pandora, play some games on Xbox Live, and watch a movie on Netflix's 
streaming service. You've spent the day on the Internet (par.

3)

A manifest attachment to the media is just the bid by an individual to make self-presentation. The new media, as much as it takes in its prevailing advantages, also holds tremendous challenges to its users. In the world today, evidence documenting digital slavery can be seen from all parts of the globe with the advent of globalisation which is exploited by the conglomerates through the illegal harvest of personal data (Ogunsola, 2005). This is underscored by Jandric \& Kuzmanic (2015) and Mule (2000) who point out that "...the reproduction of the new digital spaces is undertaken by the dominating classes as a tool for (re) production of the existing hegemonic social relationship", and they have maximally exploited the situation effectively. Consequently, this condition can be equated to physical slavery because based on Lefevbre's (1974) argument, the media world can be seen as a fully developed representation of physical, pecuniary, social and etymological terrain. People are subjugated more than ever through the internet because our life now almost depends on the internet. Jin (2015) points to this mindless symbiosis by observing that in the epoch of globalisation, platforms have also gained importance for the digital economy, as people, both as content developers and users, consistently use Facebook and Google for profit, thus becoming a new means of capital for the owners who have developed their strategies to transform daily users' actions into financial sources. The way people are attached to the new media that is dominated by the conglomerates indicates that modern slavery and imperialism is back, this time through the new media application. They are not just latent. A clearly related instance was the Cambridge Analytica scandal in 2018 when 87 million data profiles were harvested on Facebook through digital personality questions (Rogerson, 2018) and were then used for commercial purposes without authorisation. Our position here is that digital manipulation 
by the conglomerates is the extension of the hitherto territorial slavery in algorithmic guise.

\section{Digital Natives}

Digital natives, a term probably first used by Mark Prensky in 2001, describes the generation born into the internet world. They grew up where the application of the internet abounded and intermingled with their everyday intellectual, emotional and social development. This category of people are especially those born in the 1980s and 1990s. They have access to all networks and the capacity to use them effectively in their daily routine (Presky, 2001; Zur, 2011; Alexander, 2015; Rochi, 2009). As inhabitants and natural speakers of the internet language, they use the technology seamlessly, finding it challenging to inhabit the two worlds of human existence - the analogue and the digital (Ronchi, 2009). They dwell in the latter, as they have the connection to all networks and the capacity to use them to solve problems without the approval of their parents. Also, they are voracious listeners of music and watch a large dosage of movies through the media and are very creative with the devices (Palfrey and Gasser, 2008). Furthermore, they are gifted in accessing pieces of information faster through digital formats instead of printed books, as they have nascent means of assimilating new information (Stole, 2018).

Mark Prensky (2001) harps on these characteristics, pointing out that they trace information faster and multi-task through visuals and texts, performing best when connected to the internet and appreciate instant gratification. Additionally, they prefer to play games on the net instead of doing a challenging work (Prensky, 2001a, 2001b; Martins \& Mandy, 2010). The internet has redefined the lives of this net generation that it predetermines the modus that young people react to situations, produce, and accept new ideas. Consequently, this has a deep implication on their lives because as 
researchers want to prove, their brains may have been reconfigured by the media-saturated world. Accordingly, Dingly and Seychell (2015) indicate that they are openly directed by the new media which has regulated their routine. Alternately, researchers have questioned this concept of neuroplasticity as postulated by the school of Mark Prensky. They interrogated the concept based on the date, period of birth, exposure, and cognition of the digital natives. More recent exploration is required in this regard.

The internet and the new media have definite advantages in the modern world as people now use them for multiple purposes. It is estimated that in 2018, 4.1 billion people connected to the internet globally (Statistica.com, 2018), and 103 million people connected in Nigeria as of 2018 (Premium Times, 2018). The internet is so pervasive that it has permeated all ramifications of people's life.

However, critics insist that the internet is exploitative and has the vestiges of colonialism in the new guise, consequent on the ways it has appropriated and exploited our daily routine through the accumulation of personal data and the regulation of lives, that people now postulate it to new imperialism by the Global North as it was during the epoch of physical colonialism. Therefore, in response to these allegations, this paper investigates the extent that colonialism has been perpetrated by the internet through the deployment of WhatsApp on some digital natives in Nigeria. It also examines if this has aided a new phase of imperialism.

The internet is very omnipresent, especially with the digital natives who have adopted it as a modus operandi. Scholars are still researching the impact of the dependence on the internet on the psychology of digital natives. Consequently, the thrust of this paper emanates from the quest to broaden the knowledge in this area of research. Specifically, this paper seeks to give answers to the following questions: 
i. What is the level of exposure to WhatsApp and other westernbased Apps by digital natives in Lagos, Nigeria?

ii. What level of influence does WhatsApp usage have on the disposition of the digital natives?

iii. What are digital natives' perception of themselves - as slaves to the internet via WhatsApp usage or otherwise?

\section{Theoretical Framework}

Researchers have made attempts to give a theoretical explanation to the imbalance of the flow of information from the Global North to the Global South. The two theories analysed here are prominent in this regard: The Centre Periphery Theory by Prebisch (1950) and Electronic Colonialism Theory by Thomas McPhail (2006).

First is the Centre Periphery Theory. Though postulated by Raul Prebisch (1950), it has been reviewed and transformed through the years by various theorists like Gibbs (1963), John Friedman (1966), John Galtung (1971), Immanuel Wallerstein (1974) and Thomas McPhail (2006). This theory attempted to interpret the structural relationship between the Global North and Global South in most aspects of human development and concluded that there is an unequal development which has resulted in the dependence of the latter on the former.

This development has caused dependencies on world economies between the centre and the periphery countries. The use of this theory in this context could be applied in the production and distribution of media products, which are skewed against the Global South. This biased relationship is not a matter of underdevelopment, but a concept etched on the idea of well-established imperialism. Going by the model of Centre Periphery Theory, media imperialism is not consequent on culture but a process of archetypal perpetration of capitalism. Consequently, in peripheral economies, there is a low production of media consumables as they are dominated by media 
conglomerates like Google, Facebook, Netflix, CNN, Skynews, Twitter, Amazon, and a host of others led by the West. This is purported to have changed the ways we do things as well as how we think and act (McPhail, 2006). In essence, the global media relationship is determined by the inequality between structurally imbalanced partners where the Global North applies, apart from the media hegemony, military, economic and political powers to extract perpetual economic advantages from the peripheral countries. This affiliation gives them the chance to dump media consumables without any regulations and relates to the negative impact of control of the media by the western conglomerates on other peripheral nations. The Global North, through the power of the media, force their culture on the South through cultural hegemony. It is a new colonialism without physical slavery that uses the means of communication to integrate the culture of the West to the rest of the world. Consequently, other nations may rescind their indigenous culture in order to accommodate that of Europe and the United States through communication dominance.

In the same disposition, Thomas McPhail (2006) in his book Global Communication Theories, Stakeholders and Trends, builds on the theory aforementioned to propound the Electronic Colonialism Theory which posits an imbalance in the global distribution of communication products that regularly emanate from the developed nations to the Global South. Thomas McPhail points out that

Electronic colonialism represents the dependent relationship of poorer regions on the post-industrial nations established by the importation of communication hardware and foreignproduced software, along with engineers, technicians, and related information protocols that establish a set of foreign norms, values, and expectations that, to varying degrees, alter domestic cultures, habits, values, and the socialisation process itself. From comic books to satellites, computers to fax 
machines, CDs and DVDs, to the internet, a wide range of information technologies makes it easy to send and thus receive information. (p.19)

This reliance by the Global South on the North has resulted in the importation of residual social cultures, norms, values, and social milieu. He insists that whereas mercantile colonialism was done through cheap materials and labour, electronic imperialism imprisoned the mind because it is targeted at the human attitude through the conglomerates who collectively had changed the ways we do things as well as how we think and act (McPhail, 2006). These theories point to the systematic enslavement of the mind of the Global South through the new media.

The association of these theories in this study is founded on the premise that addiction of the youth to media is not due to viability but the influence of the centre on the periphery driven by modern media imperialism. WhatsApp is used as a microcosm to analyse this dependence.

\section{Literature Review}

The plethora of academic texts on this topic is overwhelming; they are all concerned about how the world, especially the digital natives and the Global South are being systematically colonised by the conglomerates. Google, Facebook, Twitter, WhatsApp, and Snapchat dominate the internet through the social media to regulate our lives. (Iqani, 2016; Dengli \& Seychell, 2015; Ebner \& Schiefner, 2010; Galtung, 1990). To further drive home this issue of the diverse and intrusive nature of the internet through Google, Noble (2018) corroborates and describes the situation luridly:

Google has become a ubiquitous entity that is synonymous for many everyday users with "the Internet" itself. From serving as a browser of the Internet to handling personal email or establishing Wi-Fi networks and broadband projects in 
municipalities across the United States, Google, unlike traditional telecommunications companies, has unprecedented access to the collection and provision of data across a variety of platforms in a highly unregulated marketplace and policy environment. We must continue to study the implications of engagement with commercial entities such as Google and what makes them so desirable to consumers, as their use is not without consequences of increased surveillance and privacy invasions and participation in hidden labor practices. (n.p)

The near total algorithmic dominance of humans enhances the total control of human life by human regulated engines.

The thrust of this section is to strategically, through a holistic approach, analyse the existing related scholarly literature on the evolution of digital colonialism and the impression on the digital natives. As extant literaturehas established, the conglomerates are engaged in one-way media flow from the north to the southern hemisphere and social content dominates the tide of information to all aspects of living that people's character are somewhat determined by these (Varis, 1984).

The same view is held by Thussu (2000) who argues that this flow has been persistent through images and ideas at the epoch that the media has been increasingly universal and with the surge of media, transnational traffic has been to the advantage of the multinationals. Though there has been recent flow of information from the south to the north with the emergence of Brazilian TV, AlJazeera and Al Arabiya, this has caused an alternative media flow. The West still regulates the area, the hierarchical media configuration - and the hegemonic monopoly will last for a long time (Guo \& Vargo, 2017).

The consequence of this is what Galtung (1990) called cultural violence on the consuming nations which will result in the violation of cultural ethos that the victimised sees it as a normal way 
of life. This is consequent on how the borderless system of the internet has rendered the regulation of the internet impotent, there seems to be no limit in regulating communication and the terms of the ITU (International Telecommunication Union) on communication have been subjugated by the media giants (Mathiason, 2009). This gives an ample chance for the controllers of the media to foist their ideas on the consumers who are mostly helpless due to the overwhelming system that forces them to consume media production that may be at variance with their philosophy of life. It is through this one-way unregulated traffic that digital natives are domesticated into the cyclical system.

This digital epoch has transformed the way people interact with one another and their immediate environment. The older analogue audience is also incorporated with the nascent culture as digital immigrants. Though they rely heavily on the analogue system, they are also sophisticated in their use of the internet. The variance is that the digital natives inhabit in their devices online without boundaries between online and off-line. Their real space, digital space and time are synchronous. This is seen as the onset of colonialism because through this there is a dependent union existing between the South. The media torrent from Europe and America drown the indigenous cultures of the universe but is worse in the Global South because of the skewed superiority of the conglomerates that regulate the media sphere in the technology and the development of media content.

Therefore, it is quite clear that the United States and Europe are focused on conquering the world through the information ascendancy (Miller, 2004). This becomes persistent because the consuming nations lack the technology and the finance to wedge the tide, though it must be given that at times there is a flow from the south to the north with the recent development in cable television technology in what seems to be a "glocalisation", where the local 
becomes global. A good example is the Al-Jazeera network from the Middle East that beams to the world and some local stations that beam into Europe and USA. This stands for the power relations who control the mind through the technological surface; hence it becomes the social reality which should be navigated carefully as the text is also a social product. As globalisation, finance, and imperialism are synchronous (Appandurai, 1996), they rely on the economic system constructed of industrial and financial projections, hence superior technology are able to dominate the economic sphere. These colonial legacies have also shaped the media consumption, deploying in the media presence outside the western world where they project imperialist stereotypes in the portrayal of the Global South.

Africa is at the receiving end of the digital expansionism. The digital native is absorbing all the traits of digital imperialism without the least awareness (Kwet, 2018). The presentation of Africa in the western media has always followed the route of subjugation, colonialism, stereotypes, racism and a particular meaning to produce a romantic representation in the terms of relations to the power to and control between Europe and the southern hemisphere. This has evolved into a systematic way of communicating and writing, which involves specific "lexical sets and syntactic structures" (Brookes, 2014) that gave rise to specific interpretations. The inability of Africa to perform in this sector of the world economy has made her a digital colony of the West, thereby her compromising sovereignty without being conscious of it. As a result, it has become a dumping place for outmoded technological programmes and goods (Omeruo, 2012). Due to this challenge, the youth is falling victim to digital colonialism because all they possess are not made in Africa. The conglomerates have come to dominate all aspects of existence. For an example, in South Africa, Google takes about $70 \%$ of local online advertising, $12 \%$ is controlled by Facebook while Netflix has a huge fellowship (Kwet, 2018). They cannot be challenged because of the lack of 
capital and technology, thereby creating cultural, social and economic hegemony. Again, the language of the internet is English; people have to scramble to learn it to manipulate the internet. Statistics show that $60 \%$ of the web content are in English and only 10-15\% of the world speak it (Mills et al, 2016). This means that a huge population also is denied access and is indirectly forced to learn the major language of the internet which is the English Language. Yet, in another typical example of digital slavery, Facebook through a program in Kenya called Free Basic, which is purported to be free internet for the growing market, pays attention to foreign content at the neglect of the local ones. This is against the net neutrality principle (Solon, 2017). The project neither serves the local needs nor does it really bring people online; all it does is data harvesting for financial purposes. A study carried out on Free Basic in Kenya indicated that the program is tilted towards western orientation. Ellergy Biddle, cited in Solon (2017), insists that Free Basics "turns the user into a mostly passive consumer of mostly western corporate content; that's digital colonialism" (p.2). The conglomerates are only pushing for their business interest through the digital means.

In Nigeria the situation seems more pathetic because of the same prevailing circumstances; the digital natives are so immersed in the new media that they are not aware of the situation in question. The imperialistic strictures have compelled most users to toe the line of the conglomerates as the continuation of the hitherto mercantile colonialism (Hamilton, 2016). It has become a continuation of physical colonialism through the internet, accepted willingly by the colonised. Nigeria has been in contact with the western media for a long time more than most African countries (Omoera, 2010) in all aspects of life. However, it must be pointed out that the western nations do not see this as an aberration because of its consistency. Also, the digitally colonised see this as normal even though they are conscious of the damage and exploitation; they are powerless to stem 
the digital invasion due to poverty and corruption that pervades the socio-political system. Nigeria has not been able to enact its media resistance; citizens are forced to depend on western media products, instead of having those produced by locals for internal consumption.

From the aforesaid, the reality of digital colonialism is evident and pervades the whole digital structure; in fact, the conglomerates depend on that for economic gains. To further clarify this situation, WhatsApp, one of the dominating media applications, is used in this study to determine the level of the pervasiveness of the digital slavery on the digital natives.

\section{Methodology}

The population for this study is undergraduates of the Pan-Atlantic University, Lagos because the school affords its students access to free Wi-Fi all day long. Given this enabling facility, students have access to data that enable them browse and use applications for chats and other purposes. Because this study focuses on digital colonialism and the presence of digital natives online, Pan-Atlantic University students provide a good fit for the study.

Pan-Atlantic University is a relatively small private school located on the outskirts of Lagos Island. The total population of PanAtlantic University undergraduate students is 700 . Working with this population, a sample size of 249 was estimated at $95 \%$ confidence level and 5\% margin of error. 249 students were recruited to participate in the study using the simple random sampling technique. Researchers sent out links to random students to give every student in the university an equal chance of being selected. At the end of the data collection period, only 129 students responded, giving a return rate of 52\% (The reason for this may be that some students would rather chat or do other things online than fill online surveys). The responses were further screened using screener measures like age (participants were expected to be between 15 and 31 years old to 
qualify as digital natives) and presence on WhatsApp. At the end, the researchers were left with only 92 valid responses.

The research instrument used to gather data was the questionnaire. The questions were based on the objectives the study sought to achieve. The researchers sent out the questionnaire via emails to students, using Google Docs. The data received were then analysed quantitatively.

Regarding the method of data analysis, quantitative data were analysed using tables and graphs, in line with the research questions posed in this paper. Different aspects of the questionnaire helped to answer the research questions, and the responses were also discussed.

\section{Analysis}

This section discusses the data gathered from the respondents of the questionnaire. The charts below present the gender and age distribution of respondents, followed by a discussion of the demographics of the study participants.

\section{Figure 1: Gender and Age Distribution of Respondents}

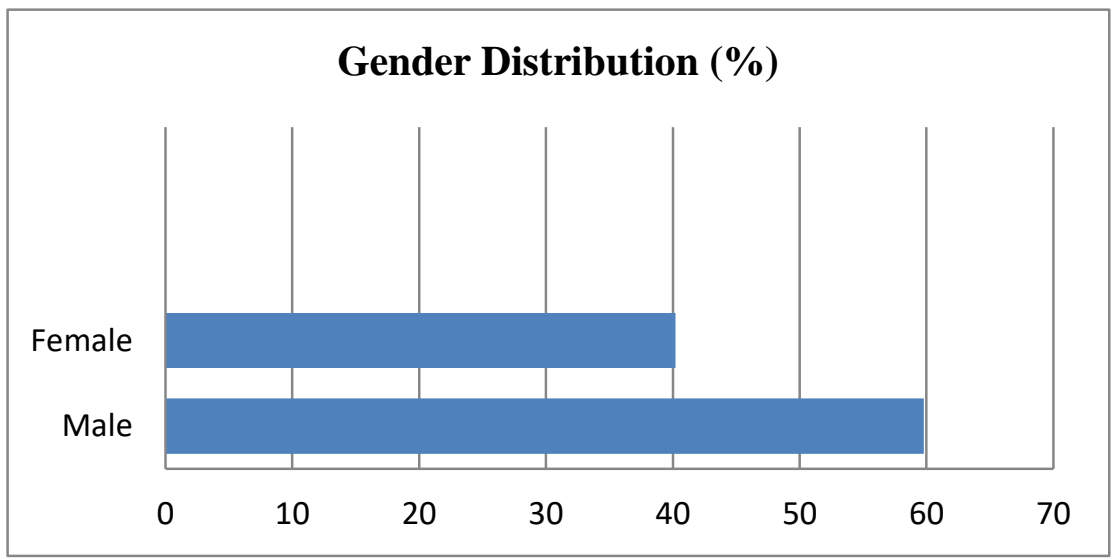




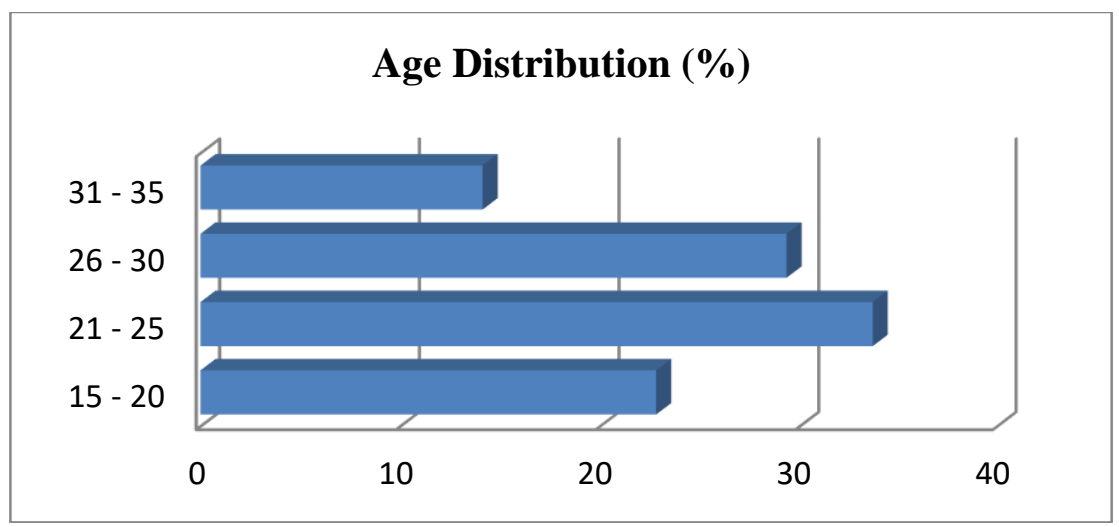

Source: Survey

At the end of administering the questionnaire via the online platform, the results collated showed that there were 55 male respondents and 37 female respondents, representing $59.78 \%$ and $40.22 \%$ respectively. Our respondents are from five out of the six geographical regions in Nigeria with South East ranking highest (42.63\%), followed by the South West $(27.9 \%)$. 99.2\% of the respondents have access to data/internet on their device, and they all have and use WhatsApp. $31 \%$ of the respondents visit the internet every 5 minutes, whereas $14.7 \%$ visit very often. Subsequently, the three research questions are addressed one after the other, using data from the respondents.

\section{Research Question One}

What is the level of exposure to WhatsApp and other western-based Apps by digital natives in Pan-Atlantic University, Lagos, Nigeria?

As shown in Table 1 below, the researchers focused their findings on the results from the 92 digital natives. There were 55 male respondents and 37 female respondents representing 59.78\% and $40.22 \%$ respectively. This is an adequate representation of male and female respondents in the digital native group. All 92 respondents use 
Oji \& Nzeaka: Digital Colonialism on Digital Natives: A WhatsApp Usage Perspective

WhatsApp, with 80 of them as active users representing $86.96 \%$. In comments to follow as responses to other questions, it is observed that many of the digital natives also use apps like Instagram and Snapchat, amongst others. This confirms that the digital natives are really aware of the almost unavoidable use of the social media, especially WhatsApp, to communicate and that they have a high level of exposure to these western-based apps.

Table 1: Age, Gender and Level of WhatsApp Use

\begin{tabular}{|c|c|c|}
\hline VARIABLES & FREQUENCY $(\mathrm{N}=92)$ & PERCENTAGE $(\%)$ \\
\hline \multicolumn{3}{|c|}{ AGE BRACKET } \\
\hline $15 \sim 20$ & 21 & $22.82 \%$ \\
\hline $21 \sim 25$ & 31 & $33.70 \%$ \\
\hline $26 \sim 30$ & 27 & $29.35 \%$ \\
\hline $31 \sim 35$ & 13 & $14.13 \%$ \\
\hline Total & 92 & $100.00 \%$ \\
\hline \multicolumn{3}{|l|}{ GENDER } \\
\hline Male & 55 & $59.78 \%$ \\
\hline Female & 37 & $40.22 \%$ \\
\hline Total & 92 & $100.00 \%$ \\
\hline \multicolumn{3}{|c|}{ ACTIVE USERS OF WHATSAPP } \\
\hline YES & 80 & $86.96 \%$ \\
\hline NO & 12 & $13.04 \%$ \\
\hline Total & 92 & $100.00 \%$ \\
\hline
\end{tabular}

From the table above, we see that 80 out of the 92 respondents affirmed to being active users of WhatsApp, which implies their 
exposure to and usage of similar apps for communication purposes. Even the remaining 12 that do not consider themselves active users of the WhatsApp do so occasionally.

\section{Research Question Two}

What level of influence does WhatsApp usage have on Digital Natives?

In addition to the above table, the optional responses allowed for in the questionnaire had 20 digital natives affirming to the level of influence WhatsApp usage has on them. They all agreed to the use of WhatsApp and the fact that it is beneficial to them in ways that include 'communicating with family and friends', 'communicating with people I can't see', 'communicating with loved ones using the video feature, especially when I am very far away from them', 'engaging, well with my friends', 'having more closed up interactions', 'chatting with persons I don't even know', and 'using it for informational purposes'.

Also, on the amount of time spent chatting using the App, in a range of $1 \sim 5,6 \sim 10,11 \sim 15$ and $16 \&$ above, a higher percentage $46.74 \%$ responded that they spend a maximum of 5 hours each day chatting on WhatsApp. We also had $19.57 \%$ respondents who use 16 and above hours daily on WhatsApp. Regarding the second research question, it may be deduced thus that there is a large amount of influence of WhatsApp usage of the digital usage, for it takes quite a significant amount of their time, for whatever purposes they deem fit for it. Their time spent on the App is captured in Table 2 and Figure 2 below. 
Oji \& Nzeaka: Digital Colonialism on Digital Natives: A WhatsApp Usage Perspective

Table 2: Time Spent Daily on Whatsapp

\begin{tabular}{|c|c|c|}
\hline \multicolumn{3}{|c|}{$\begin{array}{l}\text { AMOUNT OF HOURS SPENT ON A WHATSAPP USAGE } \\
\text { DAILY }\end{array}$} \\
\hline $1 \sim 5$ hours & 43 & $46.74 \%$ \\
\hline $6 \sim 10$ hours & 17 & $18.47 \%$ \\
\hline $11 \sim 15$ hours & 14 & $15.22 \%$ \\
\hline $16 \&$ above & 18 & $19.57 \%$ \\
\hline Total & 92 & $100.00 \%$ \\
\hline
\end{tabular}

The above table is represented in the chart below.

Figure 2: Responses on Time Spent Daily on WhatsApp

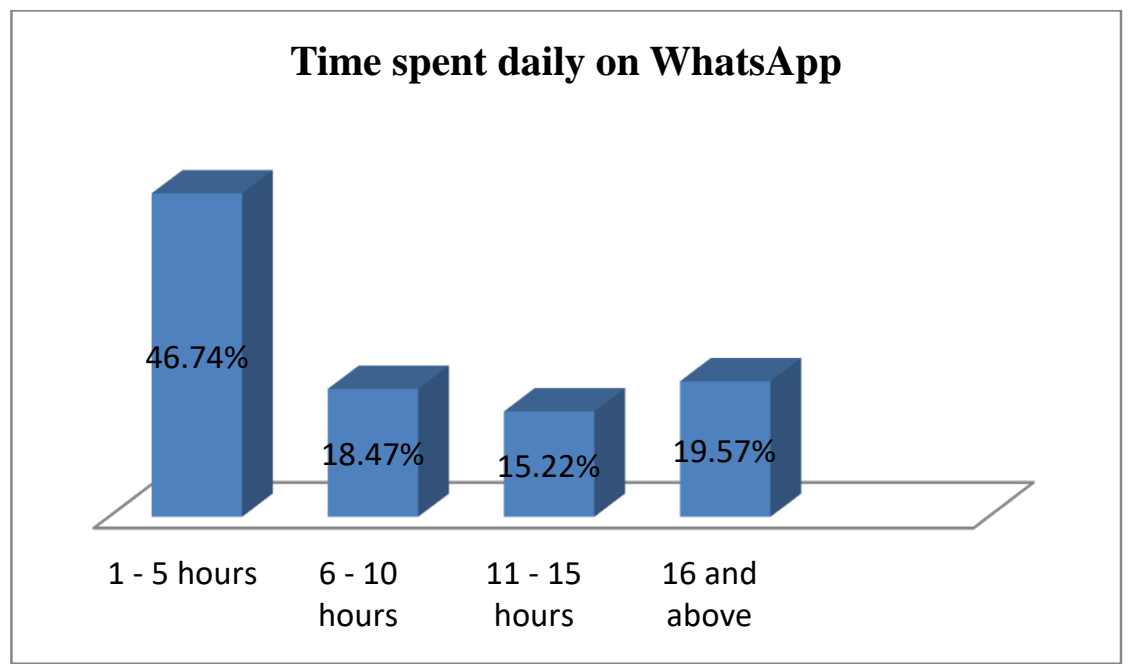

Source: Survey

\section{Research Question Three}

What perception do digital natives have of themselves - as slaves to the internet via WhatsApp usage or otherwise? 
To properly interrogate this, the natives were asked questions to ascertain their addiction or otherwise to the use of WhatsApp. Further questions were also asked to find out if they considered themselves digital slaves as a result of the benefits they derive from the use of the App. Table 3 reveals that $53.26 \%$ of the respondents do not feel that they are addicted to the use of WhatsApp whereas $28.26 \%$ responded that they are, indicating a not too engaging platform for the greater respondents.

Table 3. Addiction or Otherwise to WhatsApp Usage

\begin{tabular}{|l|l|l|}
\hline VARIABLES & $\begin{array}{l}\text { FREQUENCY } \\
(\mathrm{N}=92)\end{array}$ & PERCENTAGE $(\%)$ \\
\hline \multicolumn{2}{|l|}{ DO YOU FEEL ADDICTED TO THE USE OF WHATSAPP? } \\
\hline YES & 26 & $28.26 \%$ \\
\hline NO & 49 & $53.26 \%$ \\
\hline MAYBE & 17 & $18.48 \%$ \\
\hline Total & 92 & $100.00 \%$ \\
\hline
\end{tabular}

The above responses are represented in the bar chart below.

Figure 3: Responses to the Question Do You Feel Addicted To the Use of WhatsApp? 


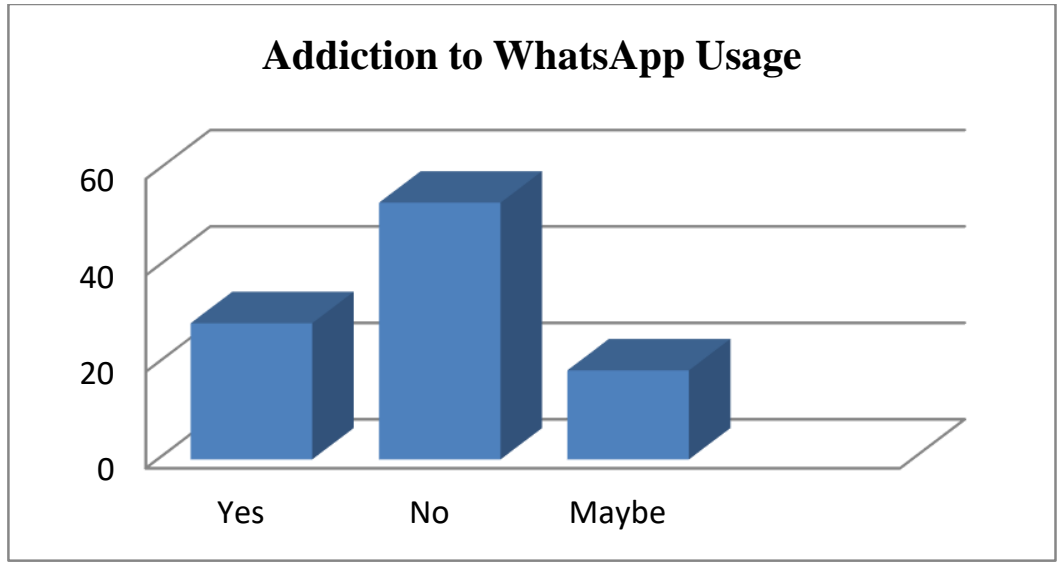

Source: Survey

In addition to responses to structured questions received via the questionnaire, optional comments by 20 respondents in line with ascertaining their addiction to WhatsApp usage or not had varied responses. Some preferred not to answer the question in clear terms but simply the following:

It can be quite distracting, "It can be quite addictive", while others clearly stated, "I used to be addicted to it until my mum helped me", "I'm not addicted to it", "Not at all. There are other social media platforms that I relate better with than WhatsApp", "No, I can always put my phone down", "I am not always on WhatsApp", "Too much of everything is bad, so I don't get glued to WhatsApp," "In fact, I check WhatsApp only twice a day", "There are many important things to be done than being on WhatsApp", "I'm not addicted to its use", "I'm not always on WhatsApp", and I barely use it. Snapchat and IG do it for me.

These responses thus show that even though there is widespread use of the App by digital natives and that a lot of time is spent by a good 
percentage, most of the digital natives studied do not consider themselves addicted to its usage.

However, examining the issue of dominance of the WhatsApp on the usage from the perspective of language of interaction on the app, Table 4 below shows that despite the ability of most of the respondents to speak and write other local languages, $88.04 \%$ of them use English language frequently to chat on WhatsApp, followed only by $8.70 \%$ who use still English language, though with Pidgin occasionally. $76.09 \%$ responded that English really has a dominating effect on them while using WhatsApp and that they experience challenges as they attempt to use other languages. The table below captures this.

Table 4. Languages Spoken and Written Fluently on WhatsApp/Language of Ease

\begin{tabular}{|c|c|c|}
\hline VARIABLES & FREQUENCY $(\mathrm{N}=92)$ & PERCENTAGE $(\%)$ \\
\hline \multicolumn{3}{|c|}{ LIST OF LANGUAGES THAT ARE SPOKEN AND WRITTEN FLUENTL } \\
\hline English Only & 30 & $32.61 \%$ \\
\hline English \& Yoruba & 17 & $18.48 \%$ \\
\hline English \& Igbo & 12 & $13.04 \%$ \\
\hline English \& Hausa & 2 & $1.55 \%$ \\
\hline English \& Pidgin & 3 & $3.26 \%$ \\
\hline English \& French & 1 & $1.08 \%$ \\
\hline Other Combinations & 27 & $29.98 \%$ \\
\hline Total & 92 & $100.00 \%$ \\
\hline \multicolumn{3}{|c|}{ EASE OF USING OTHER LANGUAGES WHILE USING WHATSAPP } \\
\hline YES & 48 & $52.17 \%$ \\
\hline NO & 44 & $47.83 \%$ \\
\hline Total & 92 & $100.00 \%$ \\
\hline
\end{tabular}


Oji \& Nzeaka: Digital Colonialism on Digital Natives: A WhatsApp Usage Perspective

LANGUAGE FREQUENTLY USED WHILE CHATTING ON WHATSAPP

\begin{tabular}{|c|c|c|}
\hline English only & 81 & $88.04 \%$ \\
\hline English \& Pidgin & 8 & $8.70 \%$ \\
\hline Others & 3 & $3.26 \%$ \\
\hline Total & 92 & $100.00 \%$ \\
\hline \multicolumn{3}{|c|}{$\begin{array}{l}\text { DO YOU FEEL MORE CONFORTABLE USING ENGLISH WHILE } \\
\text { CHATTING ON WHATSAPP? }\end{array}$} \\
\hline YES & 70 & $76.09 \%$ \\
\hline $\mathrm{NO}$ & 10 & $10.87 \%$ \\
\hline MAYBE & 12 & $13.04 \%$ \\
\hline Total & 92 & $100.00 \%$ \\
\hline
\end{tabular}

Figure 4: Language Frequently Used While Chatting on WhatsApp

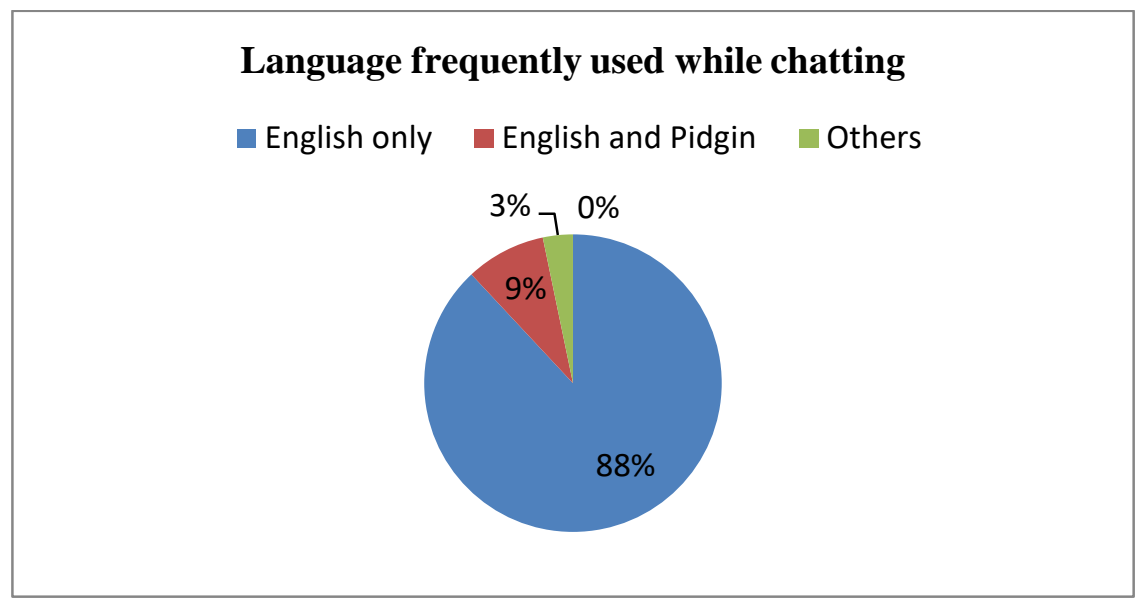

Source: Survey 
Some of the challenges experienced by the digital natives that limit their use of other languages they are fluent with include the following (as additional notations by the respondents):

"... auto correction does not easily allow a particular word to stay".

"... this is because when I chat in Igbo language, there are some necessary punctuation in Igbo language that you cannot find, which are supposed to help convey your actual meaning and intent".

"... Some languages come with some symbols and signs. Looking for those signs sometimes is tiring".

"Yes, typing in Igbo language is difficult because it's not one of the programmed language".

"Yes...I also face the problem of auto-correct when I type in any other language than English".

Table 5 below, however, shows that despite the challenges associated with chatting freely on WhatsApp, some digital natives feel that they cannot avoid its use. Such ones may thus be referred to as conscious and willing slaves to the Western digital slavery.

Table 5: Consideration of Self as Slaves Consequent on Benefits Derived from Whatsapp Usage

\begin{tabular}{|l|l|l|}
\hline SPECIFICS & CHALLENGES & BENEFITS \\
\hline & Yes, auto correction & Minimizes cost. Saves time \\
& does not easily allow & Enables delivery of bulk \\
$10 / 5 / 2018$ & a particular word to & contents. Enables visual \\
chatting. Enables voice \\
$16: 49$
\end{tabular}




\begin{tabular}{|c|c|c|}
\hline $\begin{array}{l}10 / 5 / 2018 \\
17: 26\end{array}$ & $\begin{array}{l}\text { Yes, this is because } \\
\text { when I chat in Igbo } \\
\text { language, there some } \\
\text { necessary } \\
\text { punctuation in Igbo } \\
\text { language that you } \\
\text { cannot find, which is } \\
\text { supposed to help } \\
\text { convey your actual } \\
\text { meaning and intent. }\end{array}$ & $\begin{array}{l}\text { Easy communication and } \\
\text { passage of information, as in } \\
\text { group chats and others; saves } \\
\text { you the cost of buying } \\
\text { airtime every time to make } \\
\text { calls and pass information; } \\
\text { convenience in the transfer of } \\
\text { some media files, e.g music } \\
\text { files(video and audio), } \\
\text { pictures, etc. }\end{array}$ \\
\hline $\begin{array}{l}10 / 5 / 2018 \\
22: 48\end{array}$ & $\begin{array}{l}\text { Yes, typing in Igbo } \\
\text { language is difficult } \\
\text { because it's not one } \\
\text { of the programmed } \\
\text { language }\end{array}$ & $\begin{array}{l}\text { Communication, Business } \\
\text { Advert, Entertainment and } \\
\text { Information. }\end{array}$ \\
\hline $\begin{array}{l}10 / 6 / 2018 \\
9: 23\end{array}$ & $\begin{array}{l}\text { Yes...I also face the } \\
\text { problem of auto- } \\
\text { correct when I type in } \\
\text { any other language } \\
\text { than English }\end{array}$ & $\begin{array}{l}\text { Quick dissemination of } \\
\text { information. It's cheaper. } \\
\text { It's fun to an extent }\end{array}$ \\
\hline
\end{tabular}

Additionally, based on the optional comments made by some digital natives, some had the following to say, "I don't mind being enslaved to WhatsApp usage as long as it gives me the benefits I seek", "I love using WhatsApp and will continue to use it as long as it exists", "I can do without WhatsApp", "Since I'm not addicted to it I can let it go", "My studies are more important to me", "There are other social media platforms, why be enslaved to WhatsApp?", "Somehow I am addicted. I don't mind at all", "WhatsApp does not mean much to me even though I find it useful", "Yes, I am addicted to it because it is beneficial to me." 
These comments highlight that some digital natives feel that they can really not do without the WhatsApp considering the benefits its usage provides them; however, these are insignificant compared with those that can do without ultimate dependence on WhatsApp.

\section{Discussion of Findings}

From the data presented above, it is clear that digital natives are largely exposed to the use of WhatsApp and other internet based applications. Also, they are aware of the influence of WhatsApp on them, especially in the area of using the App for communication purposes and the amount of time spent on it. Furthermore, on the issue of perceiving themselves as slaves of the digital colonialism as a consequence of the benefits derivable - which includes smooth communication, especially with loved ones far away $-18.48 \%$ of the sample are unsure, $28.26 \%$ signalled their high dependence on the App and thus their addiction to it, while an interesting 53.26\% out rightly reject the idea of being willing slaves or addicted to WhatsApp usage. Although this percentage of digital natives do not agree to be digitally colonised, they join the other natives in agreeing that irrespective of the fact that they have languages they speak and write fluently other than English, the WhatsApp is programmed in a way to allow only the convenient use of the English language, thus creating also that dominating effect which they do not want to associate with.

The Centre Periphery Theory, used as one of the framework for this study, notes an advent of media imperialism which is a perpetration of capitalism. This is obvious as we noted that from the sample population, $86.96 \%$ are active users of the WhatsApp, while the other $13.04 \%$ use it sparingly. This study finds that digital natives depend not only on WhatsApp but also on other internet apps like Instagram and Snapchat, which are also products of the Global North. Some categorically assert that they do not really need the WhatsApp and as such are not active users. But such ones are fewer compared to 
the number of those who actively use the WhatsApp. The Electronic Colonialism theory aptly supports the findings of this study as digital natives, a good number of them, widely depend on the use the WhatsApp for communication purposes but do not feel that they necessarily depend on them as ones enslaved. This does not quite agree with Prensky's (2001) view that digital natives only perform best when connected to the internet and appreciate instant gratification.

On the aspect of being slaves to the internet, digital slavery which is a sense of physical and emotional attachment to technology that it regulates one's life - is not a concept that most of the digital natives studied agree with. Moody (2014) and Illing (2018) noted that digital slaves are not able to master the technological world effectively but are rather enslaved to it. Our study, however, finds that digital natives are averse to being called slaves to the internet, especially to WhatsApp. Nevertheless, Anderson (2010) posits that from the waking hours until the end of the day, time (or the whole day) is spent on the internet by digital natives who are constantly checking their phones for whatever purposes. Perhaps, that is the thought of Prensky (2001) when he made reference to the natives seeking instant gratification. Even though most of the natives studied do not consider themselves addicted or enslaved to WhatsApp use, previous studies as here mentioned suggests that the amount of time spent can qualify one as being a slave to technology. The study finds that many of the natives spend not less than a range of 1 to 5 hours daily on WhatsApp, let alone on other internet applications.

One can, therefore, note from the findings that the digital natives in Pan-Atlantic University are highly exposed to the use of WhatsApp and other internet-based technology or applications, spend a lot of time chatting on WhatsApp - which may equate them as digital slaves, although majority do not subscribe to such marking, 
and only a few admit to being enslaved to WhatsApp use, given the benefits they derive from the technology.

\section{Conclusion}

This paper has argued that the internet is exploitative of the digital natives, and our research indicates that the challenge is relevant to the wider scholarly debates on the issue. The insight into the study deepens the understanding of the topic and gives credence to the relevance of the two theories used - The Centre Periphery Theory by Prebisch and Electronic Colonialism Theory by Thomas McPhail - to deepen their relevance.

In line with Research Question 3, 'What perception do digital natives have of themselves - as slaves to the internet via WhatsApp usage or otherwise?' more research needs to be undertaken in order to find out why they do not consider themselves as digital slaves regardless of the overwhelming evidence pointing to that direction. It can then be inferred that digital natives are aware of the influence of WhatsApp on them, but they feel that they are in control. They also are aware of some elements of digital colonialism in terms of the features that make some of them addicted to its use and the amount of time spent on it, and ultimately, the only language convenient for use on the App - the English language. These notwithstanding, it would appear that the amount of time digital natives spend on use of the WhatsApp makes them indeed digitally colonised, even though they do not agree.

\section{Recommendation}

Further studies should be directed on this subject to determine the degree of the usage of other internet-based applications by digital natives. To try out this assertion, a wider population sample - not just one, as has been used in this study - should be interrogated to ascertain the degree of reliance of the digital natives on the social 
media. This would offer a wider conception as to whether or not they are digitally colonised and governed by their extravagant reliance on internet devices. Only then can a generalisation be made to all digital natives in Nigeria.

Karachi Benson Ruth Orji

School of Media \& Communication

Pan-Atlantic University Lagos

Email: roji@pau.edu.ng

Emmanuel Ezimako Nzeaka

Pan-Atlantic University Lagos

Email: enzeaka@pau.edu.ng

\section{References}

Ali, M. S. (2017). Decolonizing information narrative: Entangled apocalyptics, algorithmic racism and the myth of history. A paper presented at IS4SI summit 12-16 June 2017 Gothenburg Sweden.

Anderson, C. (2010). The web is dead. Long live the Internet. Retrieved from www.wired.com

Appandurai, A. (1996). Modernity at large. Cultural dimensions of globalization. Minneapolis: University of Minnesota Press.

Blumenthal, P. (2018). The techno colonialism of Facebook and Cambridge Analytica. Retrieved from https://www.huffingtonpost.com/entry/facebook-cambridgeanalytica...

Cadwalladr, C. \& Harrison, G. (2018). Revealed: 5 million Facebook profiles harvested for Cambridge Analytica in a major data breach. Retrieved fromhttps://www.theguardian.com/news/2018/mar/17/cambri dge-analytica-facebook-influence-us-election 
Cchub, (2014). How Nigerian students use their phones. Retrieved from www.entrepre-news.com.

Crist, C. (2017). On the mind: What science says about digital natives. Retrieved from pastemagazine.com

Dingli, A. \& Seychell, D. (2015). The new digital natives: cutting the cord. New York: Springer

Dingli, A. \& Seychell, D. (2015). The new digital natives: Cutting the chord. New York: Springer.

Ebner, M. \& Shiefner, M. (2010). Looking towards the future of technology enhanced education: Ubiquitous learning and the digital native. New York: IGI Global.

Eijaz, A. \& Ahmad, R. E. (2011). Electronic colonialism: Outsourcing as discontent of media globalization. American Journal of Contemporary Research. 1(3) 134-143.smit from htpp://www.researchgate.net/publications/325805041

Friedman, J. (1966). Regional development policy: A case study of Venezuela. Massasuchetts: MIT Press

Galtung, J. (1990). Cultural violence. Journal of Peace and Research. 37 (3), pp. 291-305.

Galtung, J. (1971). The structural theory of imperialism. Journal of Peace Research. 146-117.

Gibbs, J. P. (1963). The evolution of population concentration. Economic Geography. 39

Guo, L. \& Vargo, C. J. (2017). Global intermedia agenda setting: A big data analysis of international news flow. Journal of Communication. 67 (4) 499-520.

Hamilton, A. (2016). Introduction to digital colonialism. Retrieved from www.i-human.com.au

Heather, N. K. (2009). Digital natives and immigrants: What brain research tell us. Retrieved from https://www.questia.com/magazine/1G1-211794589/digitalnatives-and-immigrants-what-brain-research 
Oji \& Nzeaka: Digital Colonialism on Digital Natives: A WhatsApp Usage

Illing, O. (2018). How we are becoming slaves to technology Retrieved from https://www.vox.com/science-andhealth/2018/3/27/17085282/technology-facebook-socialmedia-sherry-turkle

Iqani, M. (2016). Consumption, media and the Global South. England: Palgrave Macmillan.

Jandric, P. \& Kuzmanic, A. (2015). Digital postcolonialism. IADIS International Journal on WWW/Internet. 13, (2), pp. 34-51.

Jardin, P. \& Kuzmanic, A. (2015). Digital postcolonialism. Retrieved from http://www.iadisportal.org/ijwi/papers/2015131203.pdf

Jin, D. Y. (2015). Digital platforms, imperialism and political culture. New York: Routledge

Kwet, M. (2018). Break the hold of digital colonialism. Retrieved from https://mg.co.za/article/2018-06-29-00-break-the-holdof-digital

Lefevbre, H. (1974).The production of space. Cambridge MA: Basil Blackwell .

Lin,J. (2008). Research shows internet is rewiring brains. Retrieved from http://newsroom.ucla.edu/stories/081015_gary-smallibrain

Mathiason, J. (2009). Internet governance: The new frontier of global institutions. New York: Routledge.

McPhail, T. L. (2006). Global communication: Theories, stakeholders and trends. Oxford: Blackwell Publishers

Miller, D. (2004). Information dominance: The Philosophy of total propaganda control. In Kamalipour, Y., \& Snow, N. (Eds), War, media and propaganda: A global perspective. Maryland: Rowman and Littlefield Publishers.

Mills, A., Sambuli, N., Varon, J. \& Avila, R. (2017). Digital colonialism: A global overview. Retrieved from www.republica.com 
Moody, O. (2014). Free yourself from digital slavery. Retrieved from www.chiefrabbi.org.free-youself-from-digital-slavery-for.aday-at-least.

Muyiwa, G. K. (2015). The most popular apps in every Nigeria smartphone. Retrieved from https://techpoint.africa/2015/11/06/popular-apps-in-nigeriasmartphone

Noble, S. U. (2018). Algorithms of oppression: How search engines reinforce racism. New York: New York University Press.

Ogunsola, L. A. (2005). Information and communication technologies and the effect of globalization: twenty-first century digital slavery for developing countries myth or reality. Electronic Journal of Academic and Special Librarianship. 6, 1-2, pp. 110.

Omeruo, K. (2012) Africa: A digital colony. Retrieved from www.techtrendsng.com

Omoera, S. O. (2010). Revisiting media imperialism: A review of Nigerian television experience. Retrieved from www.researchgate.net/publication/215710892

Palfrey, J. \& Gasser, U. (2008). Born digital. New York: Basic Books.

Palfrey, J. \& Gasser, U. (2008). Born Digital: Understanding the first generation of digital natives. Pilidelphia: Basic Books.

Patson, P. (2004). Digital natives or digital colonized. Retrieved from https://www.socialworkhelper.com/.../19/digitally-native-orcolonized.

Prebisch, R.A. (1950). The economic development of Latin America and its principal problems. Santiago: ECLAC.

Premium Times. (2018). Nigerian Internet users hit 103 million. Retrieved from https://www.premiumtimesng.com/news/more-news/274828nigerias-internet-users-hit-103-million-ncc.html 
Oji \& Nzeaka: Digital Colonialism on Digital Natives: A WhatsApp Usage

Prensky, M. (2001). Digital natives and digital immigrants part 1. On the Horizon.9, 5, pp.1-6.

Prensky, M. (2001). Digital natives and digital immigrants part 2. Retrieved from www.emeraldinsight.com|doi|abs|10.1108\107481201104248 43

Rogerson, S. (2018). Digital existence: A modern way to be. Retrieved www.researchgate.net|publications $\backslash 313$

Ronchi, A. M. (2009). eCulture: Cultural content in the digital age. Berlin: Springer.

Schiefner, M. \& Martin, E. (2010). Looking towards the future of technology-enhanced

Sefundi. The Journal of South African and American Studies. 16, 2, 156-172.

Similarweb (2018). The most popular apps ranking in Nigeria. Retrieved from www.similarweb.com

Smith, J. (2017). Data is new colonialism. Retrieved from https://indvstrvs.com/data-new-colonialism/

Solon, O. (2017). It's digital colonialism: How Facebook's free internet service has failed its users. Retrieved from https://www.theguardian.com/technology/2017/jul/27/faceboo k-free-basics-developing-markets

Statista (2018). Digital global population 2018. Retrieved from https://www.statista.com/statistics/617136/digital-population.

Stole, H. (2018). Why digital natives need books: The myth of digital natives. First Monday. 23, 10, n.p.

Torbel, G. (2019). Social media can predict your behaviour even if you do not use them. Retrieved from www.digitaltrend.com/social media-/social-media-privacyfriends-prediction.

Thussu, D. K. (2007). Media on the move: Global flow and counter flow. London: Routledge. 
Varis, T. (1984). The international flow of television programs. Journal of Communication, 34(1), 143-152.

Wallerstein, I. (1974). The modern world system: Capitalist agriculture and the origin of European world economy in the sixteenth century. New York: Academy Press.

Zur, O. (2011). On the digital immigrants and digital natives: How the digital divide affects families, educational institutions and the workplace. Retrieved from www.researchgate.net $\backslash$ publications $\backslash 2672 \backslash 3208$ 